\title{
COMO O APRENDIZADO PODE SER EFETIVO COM O USO DA TÉCNICA MULTI- DIMENSIONAL DE ENSINO EM ADMINISTRAÇÃO?
}

\author{
HOW LEARNING CAN BE EFFECTIVE USING THE MULTIDIMENSIONAL TEACH- \\ ING TECHNIQUE IN BUSINESS ADMINISTRATION
}

Recebido em: $19 / 12 / 2017$ Aprovado em: 27/04/2018
Avaliado pelo sistema double blind review
Editor Científico: Edson Sadao Iizuka
DOI 10.13058/raep.2018.v19n3.903

ANDRÉA APARECIDA DA COSTAMINEIRO

Universidade Federal de Itajubá

LUIZ GUILHERME RODRIGUES ANTUNES

DANIELA MEIRELLES ANDRADE

Universidade Federal de LAVRAS

JADE VIEIRA

Universidade Federal de Itajubá

\begin{abstract}
RESUMO
O objetivo desse artigo é avaliar a aprendizagem por meio de uma nova opção de metodologia ativa, a Técnica Multidimensional de Ensino (TME), a partir da percepção dos alunos que cursaram a disciplina de Empreendedorismo Tecnológico do Curso de Administração na Universidade Federal de Itajubá no período de 2012 a 2016. Para isso, utilizou-se de estudo de caso, onde os dados foram coletados em fontes primárias de dados por meio de documentos e questionários. Os documentos são compostos por relatórios finais entregues pelos alunos da disciplina e os questionários eletrônicos autopreenchidos direcionados aos alunos que já cursaram a disciplina. Para análise de dados utilizou-se a análise de conteúdo por frequência para os documentos e, análise multivariada para os questionários, com aplicação da análise de cluster, teste ANOVA e discriminante. Entre os resultados, foram evidenciados três grupos na análise de clusters, que foram nomeados como: Apoiadores, Indiferentes ou Rejeitadores da técnica de ensino. Os resultados mais relevantes em cada dimensão, constatados na análise discriminante, são: o aprendizado sobre investidores anjos, na dimensão técnica; o desenvolvimento de sua rede de contatos e aperfeiçoamento das habilidades de comunicação dos alunos, na dimensão indivíduo. O resultado mais relevante para as empresas participantes foi a mentoria proporcionada pelos investidores anjos, percebido na dimensão sociedade. Por fim, constatou-se que $91 \%$ da amostra concordam total ou parcialmente que a TME é uma alternativa para o processo de ensino-aprendizado em Administração.
\end{abstract}

Palavras-chave: Metodologias Ativas; Técnica Multidimensional de Ensino; Curso de Administração.

ABSTRACT

The aim of this paper is to evaluate learning using a new active methodology option: the Multidimensional Teaching Technique (MTT). It is based on the perception of students who attended the Technological Entrepreneurship course as part of their Business Administration degree at the Federal University of Itajubá, from 2012 to 2016. To that end, a case study was developed using data collected from primary sources through documents and questionnaires. The documents are composed of final reports delivered by these students and self-administered electronic questionnaires addressed to students who had already taken the course. Data analysis was performed using frequency content analysis for the documents and multivariate analysis for the questionnaires, with cluster analysis, the ANOVA test and discriminant analysis. Among the results, three groups were evidenced in the cluster analysis and named: Supporters, Indifferent and Rejecters of the teaching technique. The analysis singled out the most relevant results as: learning about angel investors, in the technical dimension; while for the individual dimension, it was developing their networks and improving their communication skills. The most relevant result for the participating companies was the mentoring provided by angel investors, which was perceived in the society dimension. Finally, it was shown that $91 \%$ of the sample agrees wholly or partially that MTT is an alternative to the teaching-learning process in Business Administration.

Keywords: active methods; multidimensional teaching technique; business administration degree. 


\section{INTRODUÇÃO}

A educação desempenha múltiplas funções na sociedade e o conceito de qualidade aplicado à educação remete a duas visões complementares (DEMO, 1996; LIMA, 2007). Por um lado, tem-se a qualidade formal, expressa no desenvolvimento de habilidades instrumentais e da capacidade prática de exercitá-las e, por outro lado, a qualidade política, que se exprime na incorporação de valores humanos, os quais estão comprometidos com princípios éticos e de responsabilidade social (LIMA, 2007). Portanto, atribui-se à educação superior, a atividade de preparar os sujeitos tanto em termos de conhecimentos, habilidades e capacidades de aprendizagem para atender às demandas do mercado de trabalho, quanto para as dimensões ético-políticas do ser humano (GOERGEN, 2008).

De forma mais específica, no que se refere a educação empresarial, entende-se que a mesma tem passado por constantes mudanças. Tais mudanças estão sendo impulsionadas por custos crescentes, por avanços da tecnologia e pela rápida globalização. Isto é especialmente visível, para os cursos de Administração, nos quais modelos alternativos para o currículo tradicional de quatro anos ainda surgem (BEHARA; DAVIS, 2015).

Nesse contexto, emergem as metodologias ativas, que substituem os métodos tradicionais de aprendizagem, que são considerados modelos de educação passivos (SOUZA; IGLESIAS; PAZIN FILHO, 2014). Souza, Iglesias e Pazin Filho (2014) apontam que é necessário dar maior ênfase ao estabelecimento de relações entre sala de aula e a sociedade por meio do uso de novas tecnologias para ensino, as quais se tornam possíveis por meio de metodologias ativas.

Assim, as estratégias de ensino ativas aparecem como meios para auxiliar os professores a alterarem o modo de ensinar, ou seja, os alunos tornam-se mais ativos, autônomos e responsáveis, tanto profissional quanto socialmente pelo processo de construção do aprendizado (CHANDLER; TECKCHANDANI, 2015).

As metodologias ativas são um meio de tornar o discente, o ator principal e autônomo no processo de aprendizado. Berbel (2011) e Sou- 
za, Shiguti e Rissoli (2013) afirmam que essa metodologia parte da pedagogia problematizadora para empregar estratégias educacionais nas soluções de problemas contextualizados, conforme o conteúdo letivo. Essa metodologia procura estimular o aluno a conhecer melhor o problema, examiná-lo e gerar reflexões que resultem na proposição de soluções ou na sua resolução.

Assim, o ensino pode ser visto, portanto, como uma atividade multidimensional fundado em diferentes esferas disciplinares. Comporta-se como um fenômeno complexo focado em professores e alunos, situados em contexto. Essa multidimensionalidade ultrapassa os limites de sala de aula e requer a contínua articulação entre alunos, professores e sociedade (FRANCO; PIMENTA, 2016).

A Técnica Multidimensional de Ensino (TME) inspira-se na visão da didática multidimensional de ensino. Ela busca uma integração entre teoria, indivíduo e sociedade, além de ligar o conteúdo apresentado em sala, vivência de situações de aprendizado pessoal e resultados para a sociedade. Contudo, essa metodologia remonta a seguinte reflexão: é efetiva a geração de aprendizado pelo aluno a partir de um processo multidimensional de ensino?

Desta forma, o objetivo desse artigo é avaliar a aprendizagem por meio da TME na percepção dos alunos que cursaram a disciplina de Empreendedorismo Tecnológico do curso de Administração na Universidade Federal de Itajubá no período de 2012 a 2016. Como objetivos específicos, buscou-se: (i) verificar a avaliação dos alunos a respeito da TME e (ii) levantar os aspectos mais relevantes acerca do aprendizado ocorrido sobre teoria, indivíduo e desenvolvimento da sociedade.

Para o alcance dos objetivos deste estudo utilizou-se de abordagem qualitativa e quantitativa. Como técnica de coleta de dados utilizou-se dados primários, com uso de questionários e documentos. A análise quantitativa foi feita a partir de análise multivariada com o uso do software SPSS $^{\circledR}$ e a análise documental fundamentou-se na análise de conteúdo por frequência. Vale destacar que o uso destas técnicas teve como objetivo aumentar a credibilidade do estudo de caso. 
Esse artigo está dividido em quatro seções além desta introdução. O referencial teórico que aborda a metodologia ativa, a TME e a aprendizagem significativa. Na metodologia apresenta-se o percurso metodológico utilizado para o estudo de caso. Na sequência a análise e discussão dos resultados e por fim, as considerações finais e limitações deste estudo. 


\section{REFERENCIAL TEÓRICO}

Neste tópico são apresentados os aspectos teóricos sobre metodologia ativa, a TME e aprendizagem significativa. Ao que se referem as metodologias ativas é exposto a conceituação, princípios e diferenciação das estratégias de ensino mais tradicionais. Na TME apresentam-se os princípios da multidimensionalidade e as dimensões da técnica. Por fim, conceitua-se aprendizagem significativa e suas características no contexto da multidimensionalidade de ensino.

\section{METODOLOGIA ATIVA}

O termo metodologia tem seu registro na língua portuguesa somente no ano de 1858, e a etimologia da palavra advém do grego: metá (atrás, em seguida, por meio); hodós (caminho); elogos (ciência, arte, tratado, exposição cabal, tratamento sistemático de um tema) (ARAÚJO, 2015). De acordo com Araújo (2015) metodologia é, portanto, um tratado, disposição ou ordenamento sobre o caminho por meio do qual se pretende, por exemplo, atingir um determinado objetivo de ensino ou uma finalidade educativa.

Segundo o mesmo autor, as matrizes pedagógicas e metodológicas no Brasil envolveram as direções tradicionalistas, escolanovista, libertadora, tecnicista; e histórico-crítica, sendo a segunda (escolanovista) a relacionada com as metodologias ativas. Assim, as metodologias ativas são processos educacionais interativos de conhecimento, análises, pesquisas, exames e decisões individuais ou coletivas, cuja finalidade é encontrar soluções para problemas propostos (GOMES et al., 2010; SOUZA; SHIGUTI; RISSOLI, 2013). Entende-se, portanto, que a metodologia ativa centra-se no aluno, que se torna o ator principal no processo de aprendizagem, ao contrário das metodologias tradicionais, onde o professor é o agente protagonista no ensino (ARAÚJO, 2015). Destaca-se, então, que o papel do docente se modifica, e o mesmo passa a atuar como facilitador ou orientador para que os discentes possam, por eles mesmos, desenvolver pesquisas, reflexões e decisões, a fim de atingir objetivos estabelecidos (BERBEL, 2011). 
Essa metodologia proporciona um princípio teórico significativo: autonomia do aluno, uma vez que a educação contemporânea permite que o discente seja capaz de auto gerenciar seu processo de formação, visto que o ensino exige respeito à autonomia e à dignidade de cada sujeito, sobretudo quando esses aspectos são as bases para uma educação que considera o indivíduo como um ser que constrói a sua própria história (MITRE et al., 2008). Ainda, as metodologias ativas trabalham o processo ensino-aprendizagem por meio da imersão do estudante em experiências reais ou simuladas que exijam a solução de problemas condizentes com a prática social da área em estudo (SOUZA; SHIGUTI; RISSOLI, 2013).

As metodologias ativas se diferem das metodologias conservadoras (ou tradicionais) uma vez que, segundo Mitre et al. (2008), essas últimas estão sob forte influência do mecanicismo de inspiração cartesiana-newtoniana, fragmentada e reducionista, o que ocasionou a separação do corpo e da mente, ou seja, estabelece-se a segregação do conhecimento em blocos especializados a fim de obter eficiência técnica. Os mesmos autores reforçam que essa fragmentação aguçou a departamentalização das instituições de ensino, dos cursos e disciplinas. Obteve-se, também, no processo de ensino-aprendizagem a estimulação da reprodução do conhecimento, no qual o docente assume papel principal de transmitir o conteúdo, ao passo que, coube ao discente a retenção e repetição dos mesmos, em atitude passiva e receptiva, tornando-o mero expectador, sem a necessidade crítica e reflexiva (BEHRENS, 2005; CAPRA, 2006; MITRE et al., 2008).

Por fim, Berbel (2011) aponta que muitas são as possibilidades de metodologias ativas, com potencial para levar os alunos a uma aprendizagem ativa e autônoma. Destacam-se algumas metodologias que já vem sendo utilizadas no campo da administração, como: o método de estudo de casos, jogos empresariais, mapas conceituais, aprendizagem baseada em problemas e, mais recentemente, a TME, que é apresentada no próximo tópico. 


\section{TÉCNICA MULTIDIMENSIONAL DE ENSINO}

O ser humano é dotado de multidimensionalidade em sua existência, ou seja, os seres humanos não são movidos somente por características econômicas, mas também por um conjunto de valores sociais, culturais e éticos que pautam sua existência (SALM; LEAL, 2012). Essa característica multidimensional do ser humano o coloca como agente construtor nas organizações e no seu ambiente, e o faz buscar auto realização, não somente no caráter operativo, mas também em outras dimensões sociais do indivíduo (BONANOMI NETO, 2001; SILVA; REBELO, 2003).

A multidimensionalidade do ensino foca a perspectiva da totalidade, isto é, a TME procura criar novos significados para o processo de aprendizagem do aluno, ressaltando tanto o desenvolvimento cognitivo e comportamental do indivíduo quanto às situações que emergem para que o aprendizado tenha significado. Essa modalidade de ensino é formada por múltiplos atores, além do aluno e professor. Inclui-se, então, a sociedade, que pode ser representada por diferentes atores em um contexto oportuno para aprendizagem.

A TME não se resume em um mero desenvolvimento de conhecimentos, mas sim em um envolvimento com uma nova realidade para aprendizagem (FRANCO; PIMENTA, 2016). Tal envolvimento permite que o aluno estabeleça relações entre os objetos e os conceitos, de modo que o significado seja construído com base na teoria e no estabelecimento de conexões com a sociedade. Tais relações são articuladas numa grande teia de significados e conhecimentos (MACHADO, 2008).

Segundo Candau (2012), para que o processo de ensino-aprendizagem seja adequadamente compreendido, precisa-se analisá-lo de tal modo que articule consistentemente as dimensões humanas, teórica e política social. Em outras palavras, é preciso desenvolver um processo que permita ao aluno aprender novos conceitos (teoria), desenvolver habilidades pessoais (indivíduo), além de se envolver com o meio no qual está inserido (sociedade).

Chandler e Teckchandani (2015) complementam que um processo de ensino-aprendizagem eficiente necessita do aprimoramento 
de três áreas, quais sejam: abordagem interdisciplinar, oportunidades para o desenvolvimento de habilidades de pensamento crítico e enfoque no estudo dos conceitos de negócio em contato com o meio social. Nesse sentido, Jackson et al. (2017) complementam que os alunos cada vez mais precisam se envolver com o mundo real durante seu processo de aprendizado.

Dessa maneira, a TME é composta por três dimensões: (i) Teoria, (ii) Indivíduo e (iii) Sociedade que pode ser vista na Figura 1.

Figura 1 Técnica Multidimensional do Ensino

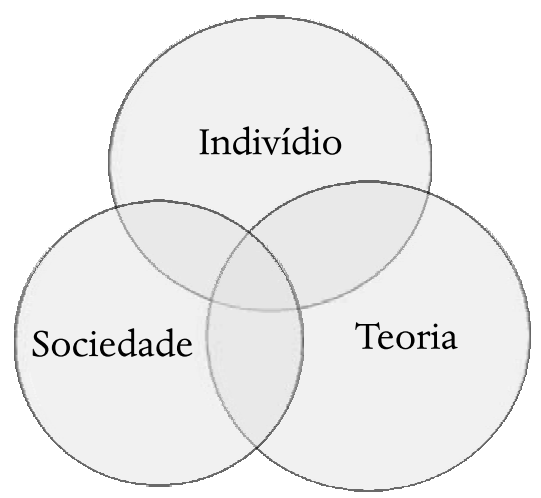

Fonte: Elaborado pelos autores

As dimensões são descritas de forma isolada, mas a sua integração reforça o processo de aprendizagem do discente. A dimensão teórica envolve todo referencial teórico que precisa ser transmitido ao aluno, a dimensão indivíduo relaciona-se às oportunidades geradas para o desenvolvimento pessoal, e a dimensão sociedade engloba o resultado proporcionado pelos alunos para a sociedade.

\section{TEORIA OU DIMENSÃO TÉCNICA}

Gomes et al. (2015) evidenciam que os principais objetivos para um processo de aprendizagem é o conteúdo aprendido e compreendido pelo discente. Para Rangel (2010), a dimensão técnica refere-se à organização 
das ações que propiciam o acesso ao conhecimento. Em outras palavras, esta vertente está relacionada com o que Libâneo (2013) apresenta como processo didático caracterizado por objetivos, conteúdos e métodos de forma a apoiar o processo de ensino e aprendizagem. Inclui-se no processo: (i) o objetivo do tema que será trabalhado; (ii) a seleção do conteúdo que será abordado; e (iii) a forma como os alunos serão avaliados. $\mathrm{O}$ aspecto conceitual, portanto, envolve o que, como e por que o conteúdo é desenvolvido de acordo com a proposta curricular da disciplina no curso (JONES, 2014). Além de considerar a forma de comunicação entre professor e alunos, que precisa ser coerente com as diferentes juventudes (FRANCO; PIMENTA, 2016).

Essa dimensão ressalta algumas características de ensino, como: aulas expositivas dialogadas e desenvolvimento do conhecimento com aplicação prática, condução de debates, a partir dos temas abordados (SOUZA; IGLESIAS; PAZIN FILHO, 2014). Gomes et al. (2015) apontam que a estrutura do curso, as disciplinas, os conteúdos, os métodos de ensino e as formas de avaliação usados em sala precisam ser coerentes com a formação almejada do administrador.

Candau (2012) reforça que o conteúdo a ser abordado e a definição de qual instrumento deve ser utilizado para construir esse conteúdo, atinge mais significado se for abordado em uma situação contextualizada. Rangel (2010) considera nessa dimensão o aspecto objetivo e racional do processo de ensino-aprendizagem. McManus (2014) reforça que o ensino de administração precisa abordar essa dimensão técnica, por frisar o pensamento racional e analítico.

\section{INDIVÍDUO OU DIMENSÃO HUMANA}

Além da dimensão técnica, Lemos et al. (2011) acrescentam que a educação do administrador precisa concentrar-se no desenvolvimento de competências e de habilidades para ocupações em instituições privadas, públicas, sem fins lucrativos ou seu próprio negócio. Além da habilidade técnica, a experiência vivida dentro e fora da universidade deve estar relacionada aos valores éticos e reflexivos. 
A prática didática mais do que ensinar conteúdo, deve preocupar-se em oferecer aos alunos oportunidades de crescimento pessoal, incluindo o desenvolvimento comportamental do indivíduo. Deste modo, o desenvolvimento de habilidades pessoais, comportamentais, éticas, interpessoais, assim como "aquisições de atitudes, tais como: valor, empatia, consideração positiva incondicional" mostram-se como parte essencial da dimensão humana do processo de aprender (CANDAU, 2012; HUMMEL; PIFAFF; ROST, 2016).

Alguns modelos buscam desenvolver habilidades pessoais, principalmente com a abordagem empreendedora que é o foco da disciplina analisada nesse trabalho, entre os modelos destacam-se: o Modelo PETRA (Project and Transference) proposto por Klein (1990) e o EMPRETEC desenvolvido pelo SEBRAE, mas inspirado na teoria de McClelland (1961). Todas as técnicas compõem um conjunto de habilidades pessoais para serem desenvolvidas nos discentes, entre elas: busca de oportunidades e iniciativa, persistência, correr riscos calculados; exigência de qualidade e eficiência, disciplina, comprometimento; busca de informações, estabelecimento de metas, planejamento e monitoramento sistemáticos, persuasão e rede de contatos, independência e autoconfiança (KLEIN, 1990; SEBRAE, 2017). Para Urias e Azeredo (2017) o mercado de trabalho valoriza habilidades como: criatividade, determinação, inovação, inteligência interpessoal, administração de conflitos, e trabalho em equipe na formação do profissional em administração.

A dimensão humana também se refere ao relacionamento humano, estabelecido na relação entre professor e alunos. Ao contrário da dimensão técnica que é classificada com uma abordagem objetiva e racional, a dimensão humana na multidimensionalidade de ensino, se apresenta como uma perspectiva subjetiva e afetiva (RANGEL, 2010).

\section{SOCIEDADE OU DIMENSÃO POLÍTICO-SOCIAL}

O ensino, de acordo com Freire (2011) e Candau (2012), não é somente transferir conhecimento, mas envolve a criação de possibilidades para a sua produção ou a sua construção. Essa criação de possibilidades vincula- 
-se com a última vertente da TME, a qual está relacionada com o contexto social ou sociedade. Em outras palavras, envolve a inserção do indivíduo, no caso o aluno, em uma organização social, em contato direto com pessoas. Essa dimensão extrapola o limite de sala de aula e acontece sempre numa cultura específica, trata com pessoas concretas que têm uma posição de classe definida na organização social em que estão inseridos (CANDAU, 2012; FRANCO; PIMENTA, 2016; JACKSON et al., 2017).

A conexão com um mundo real proporciona ao discente uma reflexão de suas experiências e envolvimento com o objeto pesquisado (JACKSON et al., 2017). O discente tem autonomia para desenvolver o seu papel no contexto que está inserido (GOMES et al., 2015). Filion (2000) reforça que o autodesenvolvimento e know-how são melhores ensinados por meio de exercícios, nos quais os estudantes definem contextos, ou seja, quando possuem contato direto com o ambiente exterior.

Friga, Bettis e Sullivan (2003) acreditam na necessidade do contato dos graduandos com o ambiente (sociedade). Para os autores quanto maior o contato com mudanças tecnológicas e demográficas, maior a capacidade de resolverem problemas e desenvolverem estratégias para a vida profissional. Cesar (2005) corrobora com os autores, informando que o contato do indivíduo com a sociedade em que está inserido, torna-se fundamental na área de ciências sociais, onde os estudos estão fundamentados na relação entre a profundidade e o tipo da experiência vivida, além da expressão e compreensão dessa experiência.

Jackson et al. (2017) e Jones (2014) apontam que o aprendizado externo a sala de aula envolve mais do que a teoria, pois os alunos aprendem sobre a cultura do local de trabalho ou da prática das comunidades que estão inseridos. $\mathrm{O}$ aprendizado acontece em situações de incerteza, mudança e contingência, o que é difícil de ser exemplificado somente na sala de aula. Jones (2014) reforça que o aprendizado é um processo de avaliação, intercâmbio e integração de novos conhecimentos com os padrões existentes do local.

Nesse sentido, Gomes et al. (2015) evidenciam que o contexto tem diferentes condições culturais, socioeconômicas e estratégicas que 
influenciam no aprendizado do aluno. Cabe ao docente intermediar as oportunidades e estímulos para que os discentes possam se envolver na sociedade e desenvolver-se nas dimensões técnica e individual (SOUZA; IGLESIAS; PAZIN FILHO, 2014). Ademais, Gossman, Powell e Neame (2017) sugerem que os alunos desenvolvam algo, uma vez que são munidos de habilidade e conhecimentos com o intuito de socializar. Tal socialização envolve maneiras pelas quais, por meio da educação, os alunos se tornam parte de contextos sociais.

A abordagem dessa dimensão é recente no ensino de administração. Para Tekarslan e Erden (2014) o ensino de administração passou por três fases durante a história. E, é apenas na terceira fase que a sociedade começou a ser vista como parte fundamental da educação em negócios.

\section{APRENDIZAGEM SIGNIFICATIVA}

Ao que se refere a teoria da aprendizagem, onde a TME está conectada, destaca-se que a mesma se liga à teoria da aprendizagem significativa. Entretanto, para entender como ocorre essa ligação, é necessário entender o que porventura, caracteriza a aprendizagem significativa.

Segundo Ausubel, Novak e Hanesian (1980), a aprendizagem significativa acontece quando novos conceitos são integrados e reestruturados na estrutura cognitiva do aprendiz, ampliando, assim, sua rede de conhecimentos. Aproxima-se a uma perspectiva da filosofia humanista, que enxergam o sujeito como um ser dotado de sentimentos, pensamentos e ações (MOREIRA, 2015), a aprendizagem significativa "subjaz a integração construtiva entre pensamento, sentimento e ação que conduz ao engrandecimento humano" (MOREIRA, 2000, p. 43). Caracteriza-se pela interação do novo conhecimento com o conhecimento prévio, de modo que a nova informação adquire significado ao aprendiz por meio da ancoragem desta em aspectos relevantes de sua estrutura cognitiva preexistente - subsunçores (PRADO; VAZ; ALMEIDA, 2012; MOREIRA, 2012), conforme dadas condições e determinado contexto (SANTOS, 2007).

Em outras palavras, a teoria da aprendizagem significativa trabalha o processo educacional sintonizado com a realidade cognitiva do aluno, 
assumindo que o estudante já possui uma estrutura mental para efetivação da assimilação do novo conteúdo a ser estabelecido nessa estrutura cognitiva (SOUZA; SHIGUTI; RISSOLI, 2013). Para Prado, Vaz e Almeida (2012) a aprendizagem significativa ocorre quando há 3 condições: (i) há presença de conceitos relevantes na estrutura cognitiva do aprendiz; (ii) o material didático tem significado lógico e psicológico; e (iii) a disposição do aluno para aprender.

Já Souza, Shiguti e Rissoli (2013) apontam que a teoria da aprendizagem significativa promove o respeito as particularidades dos alunos, que demandam processos educacionais mais justos as suas características socioculturais, requerendo uma educação mais personalizada e interativa, tais fatores, são inviáveis em um modelo de ensino-aprendizagem mais tradicional. Os autores argumentam também que essa aprendizagem quando aliada as metodologias ativas alcançam o ensino-aprendizagem eficiente e personalizado às características de cada aprendiz.

Nesse contexto, a TME considera que o aprendiz está inserido em um contexto social, cultural e econômico, com uma estrutura de significados pré-existente. A inserção do aluno num contexto prático permite que ele obtenha novos significados, por meio da aplicação da teoria e desenvolvimento de habilidades pessoais.

Em outras palavras, a técnica permite que o docente detecte, inicialmente, os subsunçores que o discente construiu durante os anos de graduação, e com base nessa estrutura cognitiva inicial, trabalhe novos significados. Estes significados são ancorados na medida em que o discente é inserido em um contexto social, a partir do qual exige-se do mesmo, maior assimilação de conhecimentos. O contexto social, também, possibilita que novos significados sejam internalizados pelos aprendizes, a partir do momento que a própria vivência das rotinas empresariais exija novas habilidades e competências dos alunos. Assim, a estrutura cognitiva inicial, permite que novas habilidades surjam no processo de aprendizado. 


\section{METODOLOGIA}

Conforme o objetivo de pesquisa, esse trabalho caracteriza-se como descritivo, uma vez que pretende detalhar os fatos e fenômenos de uma realidade o mais fiel possível, de maneira que abranja, com exatidão, as características de um indivíduo, situação, ou grupo, bem como revelar as relações entre os eventos (SELLTIZ, 1965; GIL 2010). Quanto a sua natureza, utiliza-se de métodos mistos, que combina abordagens quantitativas e qualitativas, o que proporciona uma melhor compreensão dos problemas de pesquisa do que abordagens isoladas (CRESWELL; CLARK, 2006). Como complemento, Malhotra (2011, p. 122) reforça que a pesquisa quantitativa "busca uma evidência conclusiva baseada em grandes amostras representativas e, normalmente envolve alguma análise estatística”. Já nas pesquisas qualitativas, o pesquisador está interessado em compreender quais os significados que os participantes atribuem ao fenômeno ou situação que está estudando (GODOY, 2005). Como método utilizado recorreu-se ao estudo de caso, que é um estudo empírico que investiga um fenômeno atual dentro do contexto de uma determinada realidade. Há situações em que as fronteiras entre o fenômeno e o contexto não são bem definidas, onde são utilizadas várias fontes de evidência (YIN, 2005). Apesar de suas vantagens, é importante que o pesquisador esteja ciente das dificuldades ao método, dentre elas, a de generalização de suas conclusões (LAVILLE; DIONE, 1999).

Assim, o estudo foi realizado em uma disciplina de Empreendedorismo Tecnológico do curso de Administração de Empresas da Universidade Federal de Itajubá, onde a TME é aplicada desde 2012. A disciplina ocorre no segundo semestre de cada ano, para alunos matriculados no $6^{\circ}$ período. Já participaram da disciplina cinco turmas, totalizando 167 alunos e 23 Empresas de Base Tecnológica (EBTs). Uma das atividades da disciplina envolve o desenvolvimento de um Projeto de Empreendedorismo Tecnológico, chamado Caçadores de Anjos, unindo no processo de aprendizagem alunos, docente, investidores anjos e EBTs. 
Ao que se refere às fontes e levantamento dos dados, a pesquisa utilizou de fontes primárias de dados, que são obtidas a partir da ação do pesquisador, as quais foram coletadas com base em documentos da disciplina, além da aplicação de um questionário eletrônico autopreen-

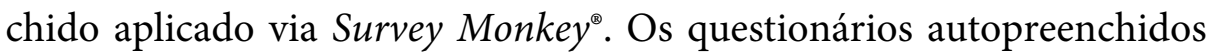
consistem em instrumentos de levantamento de dados lido e respondido diretamente pelos interrogados, não havendo a necessidade de um entrevistador (MATTAR, 2008). O propósito dos instrumentos, tanto dos relatórios finais da disciplina quanto dos questionários, foi avaliar a técnica na perspectiva da teoria, do indivíduo e da sociedade.

Os documentos são representados por 45 relatórios finais entregues pelos alunos da disciplina de Empreendedorismo Tecnológico do curso de Administração do período de 2012 a 2016. tOs relatórios finais continham as seguintes informações: (i) apresentação das EBTs que os alunos apoiaram durante o semestre; (ii) a estratégia e execução do projeto; (iii) o aprendizado teórico dos alunos; (iv) o desenvolvimento pessoal; e (v) os benefícios gerados para as EBTs. No que se refere ao questionário, o mesmo foi construído pelos autores a partir das dimensões da TME (teoria, indivíduo e sociedade) e dos resultados obtidos na análise documental. O questionário (Anexo I) foi construído em cinco blocos: informações demográficas; as três dimensões da técnica e avaliação da TME.

Foi aplicado o pré-teste ao instrumento objetivando à adequação do mesmo a partir da percepção dos alunos. Dessa forma, o pré-teste foi executado entre o dia 5 e o dia 15 de junho de 2017. Foram enviados 20 questionários aos pesquisados, e houve uma taxa de retorno de 75\% (15 questionários). Entre os resultados do pré-teste foi possível diminuir a escala do questionário, que inicialmente era de 1 a 10 pontos e passou para 1 a 5 pontos, sendo (1) discorda totalmente (ou aprendizado não adquirido ou habilidades não desenvolvidas) a (5) concorda totalmente (aprendizado muito adquirido ou habilidades bem desenvolvidas). Além da escala, as variáveis preditoras para avaliação da dimensão indivíduo diminuíram de 50 para 26, o que ocasionou na diminuição do questio- 
nário. Desta forma, o questionário foi composto por cinco partes, sendo: (i) informações gerais com nove questões; (ii) avaliação da dimensão teórica com três blocos de questões que continham 14 variáveis preditoras; (iii) avaliação da dimensão indivíduo com três blocos de questões que continham 26 variáveis preditoras; (iv) avaliação da dimensão sociedade com três blocos de questões que continham 16 variáveis preditoras; $\mathrm{e}(\mathrm{v})$ avaliação geral da técnica com um bloco de questão que continha cinco variáveis preditoras. Por fim, totalizou-se 70 variáveis no questionário, sendo nove demográficas e 61 preditoras.

$\mathrm{Na}$ composição do questionário, as questões refletiram as características para as dimensões da TME. A parte I considera os aspectos demográficos, como: sexo, ano de participação na disciplina, cidade da empresa participante. A parte II avalia a dimensão técnica e considera a teoria abordada, aspectos sobre a metodologia do professor e sistema de avaliação. A parte III envolve as habilidades desenvolvidas e os benefícios proporcionados aos alunos. A parte IV mostra o relacionamento e benefícios proporcionados à sociedade pelos alunos. Por fim, a parte V, apresenta uma avaliação geral da TME.

Para análise dos documentos (relatórios) utilizou-se de análise de conteúdo, que é um "conjunto de técnicas de análise que visa obter procedimentos sistemáticos e objetivos a descrição do conteúdo das mensagens, possui indicadores que permitem a inferência de conhecimento relativo às condições de produção/recepção dessas mensagens" (BARDIN, 2016, p. 48). Escolheu-se a análise de conteúdo por frequência, que consiste na identificação das respostas dos entrevistados e agrupamentos conforme cada pergunta, utilizando a estatística descritiva (BARDIN, 2016). Como agrupamentos utilizou-se as mesmas dimensões da TME.

Já para a análise do questionário, foi adotado técnicas multivariadas e as escalas ordinais foram assumidas como intervalares para que técnicas de análise fossem aplicadas. Foram enviados 167 questionários à população, durante o período de 17 de junho a 04 de julho de 2017, e obteve-se 73,05\% de retorno (122 questionários respondidos). Segundo Hair Jr et al. (2005) o tamanho da amostra para análise multivariada não 
deve ser menor que 50. Já, o Marconi e Lakatos (2005) reforçam que, geralmente, a taxa média de devoluções dos questionários é de $25 \%$.

No que tange ao acesso aos pesquisados, esse só foi possível pelo cadastro realizado por todos os alunos no momento que cursaram a disciplina na plataforma de comunicação com os alunos da universidade. Esse cadastro foi consultado e como a maioria dos dados estava atualizada, foi possível obter uma elevada taxa de retorno do questionário.

Para a análise multivariada, utilizou-se o software SPSS ${ }^{\oplus}$ (Statistical Package for the Social Sciences). Iniciou-se a análise com a Análise de Cluster em todos os dados com Modelo Hierárquico Ward com base em Maroco (2010) e Malhotra (2011). Na sequência, foi realizado o teste ANOVA com a finalidade de avaliar se os grupos diferem significativamente entre si com base nas médias de concordância. Por fim, foi aplicada a análise discriminante a cada bloco de variáveis considerando os clusters extraídos na etapa anterior, a fim de verificar quais eram os pontos principais que discriminavam um cluster do outro. Optou-se, portanto, por utilizar o Método Stepwise (por etapas), pois o método estima as funções discriminantes, do qual as variáveis independentes entram sequencialmente, de acordo com o poder discriminatório que elas acrescentam a precisão de pertinência no grupo (HAIR JR et al., 2005).

\section{ANÁLISE DE DADOS E DISCUSSÕES}

O estudo foi realizado na disciplina de Empreendedorismo Tecnológico do curso de Administração de Empresas da Universidade Federal de Itajubá, no qual a TME é aplicada desde 2012. Anteriormente, a disciplina adotava uma proposta tradicional onde a temática de Empreendedorismo Tecnológico era abordada por meio de seminários temáticos. A disciplina é obrigatória para os alunos que estão no $6^{\circ}$ período do curso de Administração e optativa para alunos de Engenharia após o $4^{\circ}$ período do curso. Além disso, a disciplina ocorre no segundo semestre de cada ano.

A aplicação da TME se fez necessária para trazer mais sentido ao processo de aprendizado, inserindo os alunos no contexto de Empreen- 
dedorismo Tecnológico, de forma que além do conteúdo explorado em sala (teoria), ele pudesse ter situações onde fosse possível o desenvolvimento comportamental (indivíduo) por meio da inserção em contextos tecnológicos (sociedade). Essa inserção além de auxiliar o processo de ensino aprendizagem, pela inserção em contextos externos a sala de aula, traz também benefícios à sociedade (aqui representada pelas EBTs), onde os instrumentos gerenciais desenvolvidos pelos alunos são utilizados pelas EBTs.

Esse envolvimento com a sociedade ocorre com o desenvolvimento de um projeto chamado Caçadores de Anjos. Ele tem como objetivo inserir os alunos no ambiente de Empreendedorismo Tecnológico por meio da execução de um projeto para uma EBT. Para o desenvolvimento desse projeto, as empresas beneficiadas são escolhidas pelo docente, os alunos a conhecem ao longo do semestre, desenvolvem instrumentos gerenciais para contatar investidores anjos como pitch, modelo de negócios e outros instrumentos que podem auxiliar na divulgação da EBT. Os alunos buscam investidores interessados no ramo de atuação da empresa e intermediam as reuniões iniciais entre eles. O projeto insere os alunos em ambientes tecnológicos (externos a sala de aula) para que eles entendam os problemas de gestão das EBTs, ajudem a empresa a melhorar seu modelo de negócios, e também possam interagir com outros atores além do docente.

Os resultados são apresentados considerando a percepção dos alunos quando cursaram a disciplina (análise documental) e, posteriormente, após já terem sido aprovados (análise multivariada). No tópico de discussões, os resultados obtidos são comparados com a literatura da TME. É importante destacar, que foram identificadas similaridades e divergências entre os resultados da análise documental e multivariada, $o$ que reforça a relevância de métodos mistos.

\section{ANÁLISE DOS RELATÓRIOS FINAIS ENTREGUE PELOS ALUNOS}

Para entender a percepção dos alunos sobre a TME, em suas três dimensões (técnica, indivíduo e sociedade) enquanto cursavam a disciplina, fo- 
ram analisados os 45 relatórios finais entregues pelos alunos. A estrutura do relatório envolveu um resumo da EBT participante, a estratégia e execução do projeto, o aprendizado técnico dos alunos (teoria), as oportunidades de desenvolvimento pessoal (indivíduo) e os benefícios gerados para as EBTs (sociedade).

Dos 45 relatórios analisados, nove são de alunos que cursaram a disciplina em 2012, 10 em 2013 e 2014, sete em 2015 e nove em 2016. O propósito dessa análise foi identificar nos relatórios dos alunos a avaliação do aprendizado a partir das dimensões da TME (teoria, aa indivíduo e sociedade), ou seja, entender qual o conteúdo foi assimilado pelos alunos, quais foram as habilidades pessoais desenvolvidas e quais os resultados entregues para a sociedade com o desenvolvimento do projeto na disciplina. Para isso, utilizou-se de análise de conteúdo por frequência para cada dimensão da TME.

$\mathrm{Na}$ dimensão técnica (ou teórica) considera-se o aprendizado adquirido pelos alunos que participaram do projeto a partir dos conteúdos que são propostos na ementa. A dimensão indivíduo considerou a identificação dos alunos das habilidades que foram desenvolvidas e aperfeiçoadas com a vivência no projeto. Já a sociedade, considerou os benefícios gerados às EBTs participantes a partir da percepção dos alunos. A Tabela 1 mostra os resultados mais relevantes evidenciados na análise de conteúdo nos anos de 2012 a 2016, bem como um resultado geral para os cinco anos analisados. 


\section{Tabela 1 Aprendizado nas dimensões da teoria e indivíduo e resultado} para a sociedade

$\begin{array}{ccc}\text { Ano/ } & \text { Tesultados para a } \\ \text { Dimensão } & \text { Teoria (técnica) } & \text { Sociedade }\end{array}$

- Investidores Anjos

$$
(66,6 \%) \text {; }
$$

- Ambientes de Inovação; termos técnicos

2012 da disciplina e dos negócios estudados e informações necessárias para a concretização do investimento $(33,3 \%)$.

\begin{tabular}{|c|c|c|c|}
\hline 2013 & $\begin{array}{l}\text { - Investidores Anjos } \\
\qquad(90 \%) ; \\
\text { - Startups }(60 \%) .\end{array}$ & $\begin{array}{l}\text { - Persuasão e rede de } \\
\text { contatos (100\%); } \\
\text { - Expressão oral e } \\
\text { escrita }(60 \%) \text {. }\end{array}$ & $\begin{array}{l}\text { - Elaboração do Can- } \\
\text { vas e o contato com } \\
\text { diversos investidores } \\
\qquad(90 \%) \text {; } \\
\text { - Pitches desenvolvidos } \\
\text { para as EBTs }(70 \%) \text {. }\end{array}$ \\
\hline 2014 & $\begin{array}{l}\text { - Investidores Anjos } \\
\qquad(70 \%) ; \\
\text { - Canvas, ambientes de } \\
\text { inovação e termos téc- } \\
\text { nicos }(40 \%) \text {. }\end{array}$ & $\begin{array}{c}\text { - Persuasão e rede de } \\
\text { contatos }(70 \%) ; \\
\text { - Expressão oral e } \\
\text { escrita }(60 \%) ; \\
\text { - Trabalho em equipe } \\
(50 \%) .\end{array}$ & $\begin{array}{l}\text { - Elaboração do Can- } \\
\text { vas, pitch e o contato } \\
\text { com diversos investi- } \\
\text { dores }(100 \%) .\end{array}$ \\
\hline 2015 & $\begin{array}{c}\text { - Canvas }(71,4 \%) ; \\
\text { - Pitch e conhecimento } \\
\text { de termos técnicos } \\
\qquad(57,1 \%) .\end{array}$ & $\begin{array}{l}\text { - Perseverança e capa- } \\
\text { cidade de planejamen- } \\
\text { to }(57,1 \%)\end{array}$ & $\begin{array}{c}\text { - Elaboração do Can- } \\
\text { vas, pitch, mentoria } \\
\text { dos investidores } \\
(71,4 \%) .\end{array}$ \\
\hline 2016 & - Canvas e pitch (55,5\%). & $\begin{array}{l}\text { - Persuasão e rede de } \\
\text { contatos (100\%); } \\
\text { - Capacidade de pla- } \\
\text { nejamento, trabalho } \\
\text { em equipe e iniciativa } \\
(55,5 \%)\end{array}$ & $\begin{array}{l}\text { - Contato com di- } \\
\text { versos investidores } \\
\qquad(100 \%) ; \\
\text { - Elaboração do pitch e } \\
\text { do Canvas }(66,7 \%) \text {. }\end{array}$ \\
\hline
\end{tabular}

- Melhoria do Canvas ou Plano de Negócios e Divulgação da Empresa $(44,4 \%)$. problemas $(55,5 \%)$; - Persuasão e rede de contatos $(44,4 \%)$.

escrita (comunicação), perseverança e capacidade de resolução de

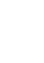

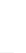




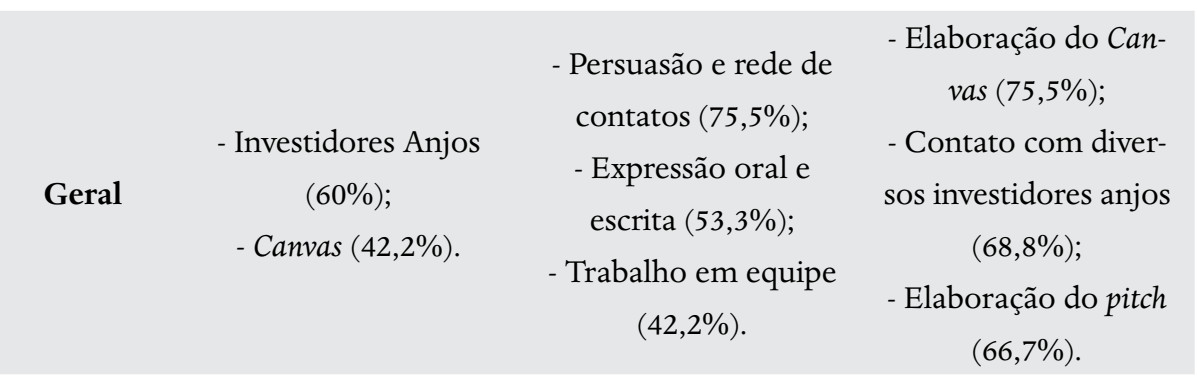

Fonte: Dados da Pesquisa

Com base na Tabela 1, percebe-se a identificação de todas as dimensões da TME pela percepção dos alunos. Na dimensão teórica, destaca-se o aprendizado dos investidores anjos que pode ser justificado pela vivência no projeto, contato com investidores e participação em eventos. $\mathrm{Na}$ dimensão indivíduo, a habilidade que obteve maior destaque foi a persuasão e rede de contatos, resultado oriundo das situações de desenvolvimento pessoal proporcionadas pelo projeto. Por fim, na dimensão sociedade, os resultados entregues para as EBTs de maior relevância são o Canvas e os contatos que são obtidos pelos alunos ao longo do semestre. As situações de aprendizado e resultados à sociedade percebidos nos documentos analisados foram criadas pela TME, e não eram visíveis em um contexto tradicional de ensino.

\section{ANÁLISE DA TÉCNICA MULTIVARIADA}

Após a análise dos documentos, o questionário foi construído tendo como foco a avaliação do aprendizado nas três dimensões da TME e uma avaliação geral da técnica. Para avaliar a efetividade do aprendizado da TME procedeu-se a análise multivariada. Após a tabulação e tratamento dos dados realizou-se a Análise de Cluster. Tal análise teve o intuito de identificar quais eram os perfis dos alunos respondentes do questionário. Como resultado, obteve-se três clusters distintos, no qual o Cluster 1 obteve 54 respondentes (44\%), o Cluster 2 obteve 58 respondentes (47\%), e o ultimo Cluster houveram 10 respondentes ( $8 \%)$. A justificativa por três clusters se dá pela possibilidade de maior de- 
talhamento sobre a avaliação dos alunos à estratégia de ensino e pela distinção entre eles.

Ademais, para estabelecer o aprofundamento do perfil dos respondentes, realizou-se o teste ANOVA, no qual os três clusters foram relacionados com as variáveis de gênero, ano que cursaram a disciplina, idade, formado ou não, repetente na disciplina ou não, cidade que executou o projeto e dedicação quinzenal. Além disso, o teste também foi realizado com as variáveis de avaliação da TME (Relação teórica entre o conteúdo e as atividades desenvolvidas no projeto; Situações de aprendizado fora da sala de aula para desenvolvimento de habilidades pessoais; Troca de experiência entre os envolvidos proporcionou benefícios; Contato com os empresários e investidores auxilia no aprendizado; e A TME é uma alternativa para o aprendizado). Estabeleceu-se como hipótese nula de que não há diferença entre os clusters. Na Tabela 2 são apontadas as variáveis significativas do referido teste, bem como suas relações com cada grupo.

Tabela 2 Perfil dos clusters segundo os respondentes

\begin{tabular}{|c|c|c|c|}
\hline & Cluster1 & Cluster2 & Cluster3 \\
\hline $\begin{array}{l}\text { Quantidade de } \\
\text { respondentes }\end{array}$ & 54 & 58 & 10 \\
\hline Gênero & Feminino $(74,1 \%)$ & $\begin{array}{l}\text { Grupo mais equi- } \\
\text { librado. Feminino } \\
(48,3 \%) \text { e masculi- } \\
\text { no }(51,7 \%) .\end{array}$ & $\begin{array}{l}\text { Masculino } \\
(100 \%)\end{array}$ \\
\hline $\begin{array}{l}\text { Relação teórica } \\
\text { entre o conteúdo } \\
\text { e as atividades } \\
\text { desenvolvidas no } \\
\text { projeto }\end{array}$ & $\begin{array}{l}98,15 \% \text { das pes- } \\
\text { soas concordam } \\
\text { total ou parcial- } \\
\text { mente. }\end{array}$ & $\begin{array}{l}\text { 72,41\% concor- } \\
\text { dam total ou } \\
\text { parcialmente, } \\
\text { porém esse grupo } \\
\text { apresenta a maior } \\
\text { parcela de pes- } \\
\text { soas indiferentes }\end{array}$ & $\begin{array}{l}70 \% \text { dos pesqui- } \\
\text { sados discordam } \\
\text { total ou parcial- } \\
\text { mente ou são } \\
\text { indiferentes. }\end{array}$ \\
\hline
\end{tabular}

$(83,3 \%)$. 


\begin{tabular}{|c|c|c|c|}
\hline $\begin{array}{l}\text { Situações de } \\
\text { aprendizado fora } \\
\text { da sala de aula } \\
\text { para desenvolvi- } \\
\text { mento de habili- } \\
\text { dades pessoais }\end{array}$ & $\begin{array}{c}98,15 \% \text { das pes- } \\
\text { soas concordam } \\
\text { total ou parcial- } \\
\text { mente. }\end{array}$ & $\begin{array}{c}82,76 \% \text { concor- } \\
\text { dam total ou } \\
\text { parcialmente, } \\
\text { porém esse grupo } \\
\text { apresenta a maior } \\
\text { parcela de pes- } \\
\text { soas indiferentes } \\
(61,5 \%) .\end{array}$ & $\begin{array}{l}80 \% \text { dos pesqui- } \\
\text { sados discordam } \\
\text { total ou parcial- } \\
\text { mente ou são } \\
\text { indiferentes. }\end{array}$ \\
\hline $\begin{array}{l}\text { Troca de expe- } \\
\text { riência entre os } \\
\text { envolvidos pro- } \\
\text { porcionou bene- } \\
\text { fícios }\end{array}$ & $\begin{array}{l}100 \% \text { das pessoas } \\
\text { concordam total } \\
\text { ou parcialmente. }\end{array}$ & $\begin{array}{c}79,31 \% \text { concor- } \\
\text { dam total ou } \\
\text { parcialmente, } \\
\text { porém esse grupo } \\
\text { apresenta a maior } \\
\text { parcela de pes- } \\
\text { soas indiferentes } \\
(80 \%) .\end{array}$ & $\begin{array}{l}70 \% \text { dos pesqui- } \\
\text { sados discordam } \\
\text { total ou parcial- } \\
\text { mente ou são } \\
\text { indiferentes. }\end{array}$ \\
\hline $\begin{array}{l}\text { Contato com os } \\
\text { empresários e in- } \\
\text { vestidores auxilia } \\
\text { no aprendizado }\end{array}$ & $\begin{array}{l}100 \% \text { das pessoas } \\
\text { concordam total } \\
\text { ou parcialmente. }\end{array}$ & $\begin{array}{c}75,86 \% \text { concor- } \\
\text { dam total ou } \\
\text { parcialmente, } \\
\text { porém esse grupo } \\
\text { apresenta a maior } \\
\text { parcela de pes- } \\
\text { soas indiferentes } \\
(90,9 \%) .\end{array}$ & $\begin{array}{l}60 \% \text { dos pesqui- } \\
\text { sados discordam } \\
\text { total ou parcial- } \\
\text { mente ou são } \\
\text { indiferentes. }\end{array}$ \\
\hline $\begin{array}{l}\text { A TME é uma } \\
\text { alternativa para } \\
\text { o aprendizado }\end{array}$ & $\begin{array}{l}100 \% \text { das pessoas } \\
\text { concordam total } \\
\text { ou parcialmente. }\end{array}$ & $\begin{array}{c}91,38 \% \text { concor- } \\
\text { dam total ou } \\
\text { parcialmente, } \\
\text { porém esse grupo } \\
\text { apresenta a maior } \\
\text { parcela de pes- } \\
\text { soas indiferentes } \\
(50 \%) .\end{array}$ & $\begin{array}{l}70 \% \text { dos pesqui- } \\
\text { sados discordam } \\
\text { totalmente ou são } \\
\text { indiferentes. }\end{array}$ \\
\hline
\end{tabular}

Fonte: Elaborado pelos autores. 
Dessa forma, pelo teste ANOVA, verificou-se que somente o gênero e as variáveis de avaliação da TME (constantes na Tabela 2) foram significativos a 5\%, conforme os pressupostos de Hair Jr. et al. (2005). Em outras palavras, tais variáveis rejeitaram a hipótese nula apontando que os clusters se diferenciam entre si. Já as outras variáveis como ano que cursaram a disciplina, idade, formado ou não, repetente na disciplina ou não, cidade que executou o projeto e dedicação quinzenal não foram significativas.

Após a análise de cluster e o teste ANOVA foi realizado a análise discriminante, cujo objetivo foi relacionar os clusters encontrados com as variáveis analisadas em cada um dos blocos de assertivas do questionário, os quais estão estruturados em três construtos: teoria, indivíduo e sociedade. Essa etapa buscou verificar quais as variáveis que discriminam um grupo do outro, pautando-se nas três categorias da TME. Ademais, aceitou-se como hipótese nula que não haveria diferenças entre os clusters quando relacionados a cada constructo (Teoria, Indivíduo e Sociedade). Os resultados apontaram a rejeição da hipótese nula nessa condição, com níveis de significância de $1 \%$ pelo teste de Lambda de Wilks, indicando que há diferenças entre os aglomerados.

Para a obtenção das variáveis discriminantes aplicou-se o Método Stepwise. Assim, obteve-se as variáveis discriminadas para cada dimensão separadamente (Teoria, Indivíduo e Sociedade), sendo as mais relevantes resumidas no Quadro 1. 


\section{Quadro 1 Resumo das Variáveis Discriminadas nas dimensões da TME}

\section{Dimensões Variáveis}

i. Informações necessárias para o Investidor Anjo: mercado alvo, potencial de negócio, concorrência, escalabilidade e time;

ii. As atividades avaliativas e seus pesos foram coerentes aos Teoria conteúdos da disciplina;

(Técnica) iii. Aprendizado sobre Investidores Anjos, Venture Capital e Private Equity;

iv. As aulas expositivas tiveram aplicação prática para o desenvolvimento do projeto;

v. Todas as avaliações foram cumpridas ao final do semestre.

i. Disciplina;

ii. Houve aprendizado do negócio, um novo ramo de atuação ou o contexto que a empresa escolhida estava inserida;

iii. Cooperação;

Indivíduo

iv. Persuasão e rede de contatos;

v. O contato com os investidores anjos ajudou numa visão prática das negociações que acontecem entre as empresas;

vi. Expressão oral e escrita (comunicação);

vii. Iniciativa;

viii. Risco calculado.

i. Os contatos com os investidores anjos, proporcionados pelo grupo, ajudaram no networking da empresa;

ii. A atividade da empresa e sua atuação no mercado ficaram claras para o grupo;

iii. Os alunos proporcionaram outras entregas para a empresa Sociedade como folders, revisão do sumário executivo, etc., que ajudaram na promoção do negócio;

iv. O grupo buscou contatos além dos investidores anjos para auxiliar nos negócios da empresa;

v. Os investidores anjos, intermediados pelo grupo, ajudaram a empresa com mentorias sobre o foco do negócio.

Fonte: Dados da Pesquisa. 
Após a análise discriminante para cada dimensão, foi possível identificar que na dimensão “Teoria”, tem-se que a mesma apresentou correlação canônica para a primeira função discriminante de 0,727 (o que indica alto grau de associação entre a função) e para a segunda foi de 0,439. Além disso, 73,8\% dos respondentes apresentaram as características do seu respectivo cluster, indicando que as variáveis foram classificadas corretamente e são capazes de discriminar os clusters. Para a função discriminante das variáveis na dimensão "Indivíduo", tem-se que a correlação canônica para a primeira função discriminante foi de 0,865 e, para a segunda foi de 0,595 . Ademais, $86,9 \%$ dos respondentes apresentaram as características do seu respectivo cluster, o que evidencia que as variáveis foram capazes de discriminar os clusters. Já na função discriminante das variáveis no aspecto "Sociedade", a correlação canônica para a primeira função discriminante foi de 0,694 e, para a segunda foi de 0,315 , onde $70,5 \%$ dos respondentes apresentaram as mesmas características do seu respectivo cluster, indicando que as variáveis foram capazes de discriminar os clusters.

Para finalizar o uso das técnicas multivariadas, foi estabelecida a nomeação dos respectivos clusters. Dessa forma, pode-se considerar o cluster 1 como 'Apoiadores', uma vez que os sujeitos desse grupo são predominantemente mulheres e aprovam total ou parcialmente o uso da TME e acreditam que a mesma é uma alternativa para o aprendizado, pois relacionam conteúdos e práticas, o que proporciona maior contato dos estudantes com o ambiente empresarial, além de trazer benefícios aos envolvidos com a técnica. Ademais, verificou-se que as mesmas concordaram total ou parcialmente sobre a efetividade das variáveis discriminadas. O cluster 2, denominado como 'Indiferentes', compõe-se tanto por homens quanto por mulheres, e são indiferentes a técnica. Em outras palavras, por mais que a maioria dos respondentes desse grupo aprove a técnica, uma grande parcela dos indiferentes a técnica se concentram nesse grupo, diferentemente dos outros clusters, por isso a distinção em 3 grupos. Em relação as variáveis discriminadas, esse grupo concordou total ou parcialmente sobre a efetividade das variáveis discriminadas, 
porém com ressalvas para "o contato com os investidores anjos ajudou numa visão prática das negociações que acontecem entre as empresas", em que a maioria dos respondentes desse grupo discordaram total ou parcialmente da afirmativa.

Por fim, o cluster 3 foi nomeado como 'Rejeitadores', visto que os sujeitos, homens, não concordam que a técnica promova o aprendizado. Além disso, não acreditam que a técnica propicia o desenvolvimento de habilidades. Ademais não concordaram total ou parcialmente ou são indiferentes em relação à efetividade das variáveis discriminadas. 


\section{DISCUSSÃO DOS RESULTADOS}

O objetivo do estudo foi avaliar a aprendizagem, por meio da TME, a partir da percepção dos alunos que cursaram a disciplina de Empreendedorismo Tecnológico, do curso de Administração na Universidade Federal de Itajubá. Evidenciou-se que a disciplina analisada procura proporcionar o aprendizado pela inserção dos alunos no contexto de aprendizado externo à sala de aula. Tal aspecto é corroborado por Freire (2011) que menciona que o ensino não é somente a transmissão do conhecimento, mas a criação de possibilidades para a sua construção. Para Franco e Pimenta (2016), bem como Jackson et al. (2017) e Jones (2014), a didática transcende o espaço escolar para fortalecer o aprendizado, por meio de problemas existentes na sociedade. Essa afirmação concretiza-se no projeto Caçadores de Anjos, onde o aluno se insere no contexto das EBTs para auxiliá-los na busca por investimento. Esse auxílio envolve os alunos na construção de diversos instrumentos gerenciais que proporcionam o seu aprendizado, bem como preparam as próprias EBTs para a busca de fomento.

As dimensões da técnica de ensino, como mencionadas por Candau (2012), Chandler e Teckchandani (2015) e Franco e Pimenta (2016), envolvem a teoria, indivíduo e sociedade. Elas são evidenciadas na disciplina por meio de aulas expositivas dialogadas, com posterior aplicação prática. Assim, as situações externas produzidas pelo projeto auxiliam o aluno em seu processo de desenvolvimento pessoal, e os instrumentos e contatos gerados pelos alunos para as empresas refletem no seu aprendizado e retorno para a sociedade, neste caso, representada pelas EBTs. Conforme os dados obtidos da análise documental e multivariada, foi possível verificar alguns pontos convergentes e divergentes a respeito da avaliação da TME, sobretudo as dimensões. Os pontos convergentes são resumidos no Quadro 2. 
Quadro 2 Resumo dos Resultados para as dimensões da TME

\begin{tabular}{|c|c|c|}
\hline Dimensões & Análise Documental & $\begin{array}{c}\text { Análise Multivariada } \\
\text { (Discriminante) }\end{array}$ \\
\hline $\begin{array}{c}\text { Teoria } \\
\text { (Aprendizado } \\
\text { mais } \\
\text { relevante) }\end{array}$ & $\begin{array}{ll}\text { i. } & \text { Investidores Anjos } \\
& (60 \%) ; \\
\text { ii. } & \text { Desenvolvimento do } \\
& \text { Canvas }(42,2 \%) .\end{array}$ & $\begin{array}{l}\text { iii. (i) Informações necessárias } \\
\text { para o Investidor Anjo: mercado } \\
\text { alvo, potencial de negócio, con- } \\
\text { corrência, escalabilidade e time; } \\
\text { iv. (ii) Aprendizado sobre Inves- } \\
\text { tidores Anjos, Venture Capital e } \\
\text { Private Equity. }\end{array}$ \\
\hline $\begin{array}{c}\text { Indivíduo } \\
\text { (Habilidades } \\
\text { mais } \\
\text { desenvolvidas) }\end{array}$ & $\begin{array}{ll}\text { i. } & \text { Persuasão e rede de } \\
\text { contatos }(75,5 \%) ; \\
\text { ii. } & \text { Expressão oral e } \\
& \text { escrita }(53,3 \%) \text {; } \\
\text { iii. } & \text { Trabalho em equi- } \\
& \text { pe }(42,2 \%) .\end{array}$ & $\begin{array}{l}\text { i. Disciplina; } \\
\text { iv. Cooperação; } \\
\text { v. Persuasão e rede de contatos; } \\
\text { vi. Expressão oral e escrita (comu- } \\
\quad \text { nicação); } \\
\text { vii. Iniciativa. }\end{array}$ \\
\hline $\begin{array}{l}\text { Sociedade } \\
\text { (Resultado } \\
\text { mais } \\
\text { relevante) }\end{array}$ & $\begin{array}{ll}\text { i. } & \text { Elaboração do Can- } \\
& \text { vas }(75,5 \%) ; \\
\text { ii. } & \text { Contato com di- } \\
& \text { versos investidores } \\
& \text { anjos }(68,8 \%) ; \\
\text { iii. } & \text { Elaboração do pitch } \\
& (66,7 \%) .\end{array}$ & $\begin{array}{l}\text { i. Os contatos com os investidores } \\
\text { anjos, proporcionados pelo gru- } \\
\text { po, ajudaram no networking da } \\
\text { empresa; } \\
\text { ii. Os alunos proporcionaram } \\
\text { outras entregas para a empresa } \\
\text { como folders, revisão do sumário } \\
\text { executivo, etc., que ajudaram na } \\
\text { promoção do negócio; } \\
\text { iii. O grupo buscou contatos além } \\
\text { dos investidores anjos para auxi- } \\
\text { liar nos negócios da empresa; } \\
\text { iv. Os investidores anjos, interme- } \\
\text { diados pelo grupo, ajudaram a } \\
\text { empresa com mentorias sobre o } \\
\text { foco do negócio. }\end{array}$ \\
\hline
\end{tabular}

Fonte: Dados da Pesquisa 
$\mathrm{Na}$ dimensão teórica ou técnica, como abordado por Candau (2012) e McManus (2014) mostra a proposta teórica que deve ser construída para o aluno, na análise discriminante, as variáveis de aprendizado teórico mais relevantes foram: (i) as informações necessárias para o Investidor Anjo (mercado alvo, potencial de negócio, concorrência, escalabilidade e time), e (ii) Aprendizado sobre Investidores Anjos, Venture Capital e Private Equity. Na avaliação documental dos cinco anos, constatou-se que o aprendizado sobre investidores anjos também predomina na dimensão teórica com 60\%, a maior evidência está nos anos de 2012, 2013 e 2014. Candau (2012) e Rangel (2010) apontam que o conteúdo a ser trabalhado atinge mais significado quando abordado de forma contextualizada, isso é evidenciado na análise de clusters, onde a maioria dos Aprovadores e Indiferentes, que representam 91\% da amostra, concordam total ou parcialmente que há 'relação teórica entre o conteúdo e as atividades desenvolvidas no projeto' e que o 'Contato com os empresários e investidores auxilia no aprendizado'. Tal resultado já fôra esperado, visto que o objetivo principal do projeto em relação as EBTs é estabelecer uma relação entre a startup ou EBT com o investidor anjo. O contato com os investidores é uma oportunidade para amadurecimento da EBT e também abre a possibilidade de aprendizado para os alunos, tanto no que se refere a preparação da EBT para as reuniões com investidores quanto aos pontos de melhoria apontados pelo investidor para a empresa.

$\mathrm{Na}$ dimensão indivíduo o aprendizado está nas oportunidades de crescimento pessoal, onde há um processo de desenvolvimento comportamental do indivíduo (CANDAU, 2012). A partir da análise documental constatou-se que as habilidades mais desenvolvidas nos alunos, são: (i) persuasão e rede de contatos (75,5\%); (ii) expressão oral e escrita (53,3\%); e (iii) trabalho em equipe (42,2\%). A análise discriminante confirmou as descobertas da análise documental que apontou as variáveis 'Persuasão e rede de contatos' e 'Expressão oral e escrita' como mais significativas na diferenciação dos clusters. No que se refere a 'persuasão e rede de contatos' e 'expressão oral e escrita', tal resultado já fôra esperado, uma vez que ao se trabalhar com investidores anjos e convencê-los a co- 
nhecer as EBTs do projeto, foi necessário que os alunos desenvolvessem suas habilidades de persuasão e comunicação tanto oral quanto escrita. No mesmo sentido, uma vez estabelecido o contato com os investidores anjos, os alunos acabavam por ampliar suas redes de contatos. Já as habilidades coordenação, determinação, cooperação, integração, liderança emergencial e disciplina não foram mencionadas na análise documental e também não se mostraram significativas na análise discriminante. A abordagem de clusters também evidencia que os Aprovadores e Indiferentes concordam total ou parcialmente que as 'Situações de aprendizado fora da sala de aula auxiliam no desenvolvimento de habilidades pessoais' que é o propósito dessa dimensão.

Já a dimensão Sociedade envolve o contato com a comunidade pelos alunos, para que a teoria seja aprendida de forma contextualizada (FRIGA; BETTIS; SULLIVAN, 2003; FREIRE, 2011; CANDAU, 2012). $\mathrm{Na}$ análise discriminante e documental, o resultado de que os investidores anjos, intermediados pelo grupo, ajudaram a empresa com mentorias sobre o foco do negócio' foi convergente. Tal aspecto também foi esperado na pesquisa, pois as relações entre as EBTs e investidores anjos auxiliaram as EBTs na definição de suas estratégias mercadológicas e acesso ao mercado, além de orientar o processo de desenvolvimento do produto. Contudo, pela análise documental, percebe-se também, a representatividade pelos discentes, no que diz respeito à elaboração e melhoria do Canvas $(75,5 \%)$, o contato com diversos investidores anjos (68,8\%) e a elaboração do pitch (66,7\%). Cesar (2007) afirma que o contato do indivíduo com a sociedade ajuda no desenvolvimento de um aprendizado prático, isso corrobora na análise de cluster, onde tanto os Aprovadores quanto os Indiferentes concordam total ou parcialmente que a 'troca de experiência entre os envolvidos proporcionou benefícios para as partes envolvidas' e o 'contato com os empresários e investidores auxilia no aprendizado'.

Demo (1996) e Lima (2007) sugerem que a educação desempenha múltiplas funções na sociedade, o que é evidenciado no estudo. Constata-se a importância da universidade no contexto social e a possibilidade de retorno efetivo para as EBTs participantes, a partir de uma disciplina. 
O aprendizado dos alunos se torna significativo, pois a teoria é contextualizada e o discente percebe a utilidade dos instrumentos gerenciais que são criados e dos contatos com investidores proporcionados às empresas. As situações vivenciadas pelos alunos no decorrer do projeto, são relevantes para o seu desenvolvimento pessoal e fortalece a importância da prática na formação do profissional em Administração.

Por fim, outras variáveis foram identificadas na análise documental e são convergentes com os construtos, porém não foram expostas como relevantes na análise discriminante. No construto teoria, destacam-se as variáveis de 'Aprendizados sobre ambientes de inovação: incubadoras, parques tecnológicos e aceleradoras', 'termos técnicos da disciplina e/ou negócios' e 'utilização e elaboração do Canvas e Pitches'. No construto indivíduo, destacaram-se as variáveis de 'capacidade de solucionar problemas', 'trabalho em equipe', 'perseverança' e 'capacidade de planejamento'. Na sociedade, a variável destacada é que 'a empresa melhorou seu modelo de negócio ou plano de negócio a partir dos contatos proporcionados pelos alunos'. 


\section{CONSIDERAÇÕES FINAIS}

As metodologias ativas estão centradas no aluno, como ator principal do processo de aprendizado (ARAÚJO, 2015). Caracterizam-se por serem processos educacionais interativos de conhecimento que tem como foco a busca de soluções para problemas propostos (GOMES et al., 2010; SOUZA; SHIGUTI; RISSOLI, 2013). A TME evidenciada no estudo além de ser uma metodologia de aprendizado ativa, busca trabalhar a dimensão teoria, indivíduo e sociedade como um processo integrativo. Há o aprendizado de uma teoria em sala, inserção em uma EBT e criação de situações onde é estimulado o desenvolvimento pessoal.

O objetivo desse artigo foi avaliar a aprendizagem por meio da TME, a partir da percepção dos alunos, participantes da disciplina de Empreendedorismo Tecnológico do Curso de Administração na Universidade Federal de Itajubá no período de 2012 a 2016. Para o alcance do objetivo utilizou-se de questionários e documentos como estratégia de coleta de dados. Os documentos foram analisados por meio de análise de conteúdo e os questionários pela técnica multivariada de dados, utilizando-se assim de métodos mistos para aumentar a credibilidade do estudo de caso.

Considerando o primeiro objetivo específico, verificar a avaliação do aprendizado dos alunos a respeito da TME, utilizou-se a análise de cluster. Evidenciou-se que os públicos denominados de Aprovadores e Indiferentes, que representam $91 \%$ da amostra, concordam total ou parcialmente que a estratégia de ensino é uma alternativa para o aprendizado em Administração. Essa constatação se mostra relevante, pois esse estudo foca na percepção dos alunos sobre seus processos de aprendizado e há um reconhecimento da efetividade do aprendizado tanto na fase de avaliação, que foi detectada na análise dos relatórios finais, quanto na resposta ao questionário depois de ter vivenciado a disciplina.

Para o segundo objetivo específico, levantar os aspectos mais relevantes acerca do aprendizado ocorrido sobre teoria, indivíduo e socie- 
dade, os aspectos destacados da TME na dimensão teoria que foram evidenciados na análise discriminante são o aprendizado sobre as 'informações necessárias para o Investidor Anjoe' 'Aprendizado sobre Investidores Anjos, Venture Capital e Private Equity'. O aprendizado sobre investidores anjos também predomina da análise documental. Na dimensão indivíduo destacou-se o desenvolvimento da 'Persuasão e Rede de Contatos' e a comunicação representada pela 'Expressão oral e escrita' confirmadas nas análises (multivariada e documental). Já a dimensão sociedade, o maior resultado entregue as empresas foi a ajuda com mentorias sobre o foco do negócio proporcionadas pelos investidores'. A análise documental também evidencia a elaboração e melhoria do Canvas, o contato com diversos investidores anjos e a elaboração do pitch como parte dos resultados produzidos para e empresa.

Franco e Pimenta (2016) afirmam que para concretizar o ensino em sala de aula é necessário transcender os limites da mesma. Tal aspecto foi comprovado na análise de clusters pelos Aprovadores e Indiferentes ao concordarem total ou parcialmente que a 'troca de experiência entre os envolvidos proporcionam benefícios para alunos, empresários e investidores' e o 'contato com os empresários e investidores auxiliam no aprendizado'.

Por fim, é possível afirmar que o objetivo geral do artigo foi alcançado, uma vez que foi evidenciado o aprendizado dos alunos por meio da TME. Esta é uma metodologia ativa e efetiva para o aprendizado significativo do aluno, pois a inserção dos mesmos nos ambientes de aprendizagem proporciona diferentes oportunidades para desenvolvimento teórico, comportamental, além de trazer benefícios à sociedade.

Entre as principais contribuições deste artigo ressalta-se a efetividade da TME como alternativa para o processo de ensino-aprendizado para a administração, a inserção dos alunos em contextos externos a sala de aula para proporcionar um aprendizado significativo, abordagem de uma metodologia de ensino que, além do aprendizado aos alunos, propicia retorno à sociedade, e também sugere-se uma metodologia de avaliação da aprendizagem a partir dos métodos mistos. 
Entre as limitações dessa pesquisa encontra-se a percepção somente dos alunos na avaliação da técnica e não considera outras variáveis que podem interferir no processo de aprendizagem nos anos analisados. Os resultados devem ser analisados com cautela, pois se baseiam somente em uma disciplina e não permite generalizações.

Como proposições de trabalhos futuros, sugere-se avaliar a percepção das empresas participantes e também do docente da disciplina para efetivar os resultados gerados a sociedade, a validação estatística dos constructos do questionário, e também avaliar os resultados dessa técnica com a aplicação em diferentes contextos. 


\section{REFERÊNCIAS}

ARAUJO, J. C. S. Fundamentos da Metodologia de Ensino Ativa. In: REUNIÃO NACIONAL DA ANPEd (37), 2015, Florianópolis. Anais... Florianópolis: ANPEd, 2015.

AUSUBEL D. P.; NOVAK J. D.; HANESIAN H. Psicologia da Educação. Rio de Janeiro: Interamericana, 1980.

BARDIN, L. Análise de Conteúdo. Tradução: Luís Antero Reto e Augusto Pinheiro. São Paulo: Edições 70, 2016.

BEHARA, R. S.; DAVIS, M. M. Navigating Disruptive Innovation in Undergraduate Business Education. Journal of Innovative Education. v. 13, n. 3, p. 305-326, 2015.

BEHRENS M. A. O Paradigma Emergente e a Prática Pedagógica. Petrópolis: Vozes, 2005.

BERBEL, N. A. N. As Metodologias Ativas e a Promoção da Autonomia dos Estudantes. Semina: Ciências Sociais e Humanas, v. 32, n. 1, p. 25-39, 2011. DOI: http:/ / dx.doi.or$\mathrm{g} / 10.5433 / 1679-0383.2011 \mathrm{v} 32 \mathrm{n} 1 \mathrm{p} 25$

BONANOMI NETO, A. O Paradigma Econômico e a Multidimensionalidade humana. Revista de Ciências da Administração, v. 3, n. 6, p. 9-20, 2001.

CANDAU, V. M. A Didática e a Formação de Educadores - da Exaltação à Negação: a busca da relevância. 33. ed. Petrópolis: Vozes, 2012.

CAPRA F. O Ponto da Mutação: a Ciência, a Sociedade e a Cultura Emergente. São Paulo: Cultrixo, 2006.

CÉSAR, A. M. R. V. C. Método do Estudo de Caso (Case Studies) ou Método do Caso (Teaching cases)? Uma Análise dos Dois Métodos no Ensino e Pesquisa em Administração. Revista Eletrônica Mackenzie de Casos, v. 1, n. 1, 2005.

CHANDLER, J. D.; TECKCHANDANI, A. Using Social Constructivist Pedagogy to Implement Liberal Learning in Business Education. Journal of Innovative Education, v.13, n. 3 p. $327-348,2015$. DOI: $10.1111 /$ dsji. 12073

CRESWELL, J. W.; CLARK, V. L. P. Designing and Conducting Mixed Methods Research. Thousand Oaks, CA: Sage, 2006.

DEMO, P. Avaliação sob o Olhar Propedêutico. Campinas: Papirus, 1996.

FILION, L. J. Empreendedorismo e Gerenciamento: Processos Distintos, porém Complementares. Revista de Administração de Empresas, v. 7, n. 2, p. 2-7, 2000. DOI http:/ / dx.doi. org/10.1590/S0034-75902000000300013.

FRANCO, M. A. S.; PIMENTA, S. G. Didática Multidimensional: Por uma Sistematização Conceitual. Educação \& Sociedade, v. 37, n. 135, p. 539-553, 2016. DOI http:/ / dx.doi. org/10.1590/ES0101-73302016136048.

FREIRE, P. Pedagogia da Autonomia: Saberes Necessários à Prática Educativa. 43. ed. São 
Paulo: Editora Paz e Terra. 2011.

FRIGA, P. N.; BETTIS, R. A.; SULLIVAN, R. S. Changes in Graduate Management Education and New Business School Strategies for the 21st Century. Academy of Management, v. 2, n. 3, 2003.

GIL, A. C. Métodos e técnicas de pesquisa social. 6. ed. São Paulo: Atlas, 2010.

GODOY, A. S. Refletindo sobre Critérios de Qualidade da Pesquisa Qualitativa. Revista Eletrônica de Gestão Organizacional, v. 3, n. 2, p. 80-89, 2005.

GOERGEN, P. Educação Superior entre Formação e Performance. Avaliação, v. 13, n. 3, p. 809- 815, 2008. DOI http:// dx.doi.org/10.1590/S1414-40772008000300010.

GOMES, G. R. S. et al. Estilos de Aprendizagem de Alunos de Cursos de Graduação em Administração: Uma Análise Multidimensional. ENCONTRO DA ASSOCIAÇÃO NACIOANL DE PÓS-GRADUAÇAO E PESQUISA EM ADMINISTRAÇÃO (39), 2015, Belo Horizonte, Anais... Belo Horizonte: ENANPAD, 2015.

GOMES, M. P. C. et al. O uso de Metodologias Ativas no Ensino de Graduação nas Ciências Sociais e da Saúde: Avaliação dos Estudantes. Ciência \& Educação, v. 16, n. 1, p. 181198, 2010. DOI http:// dx.doi.org/10.1590/S1516-73132010000100011.

GOSSMAN, P.; POWELL, S.; NEAME, C. Pain, Gain - Mission. Higher Education Pedagogies. v. 3, n. 1, p. 7-9, 2017. https:/ / doi.org/10.1080/23752696.2017.1413669

HAIR JR., J. F. et al. Análise Multivariada de Dados. Porto Alegre: Bookman, 2005.

HUMMEL, K.; PIFAFF, D.; ROST, K. Does Economics and Business Education Wash Away Moral Judgment Competence? Journal of Business Ethics, v. 150, n. 2, p. 559-577, 2016.

JACKSON, J. ET AL. HOW BEST TO ASSESS STUDENTS TAKING WORK PLACEMENTS? AN EMPIRICAL INVESTIGATION FROM AUSTRALIAN URBAN AND REGIONAL PLANNING. Higher Education Pedagogies. v. 2, n. 1, p.131-150, 2017. https: / / doi.org/10.1080/23752696.2017.1394167

JONES, A. Perspectives on Change: A Study of the Multiple Dimensions of Changing Teaching. Teaching in Higher Education. v. 19, n. 2, p. 170-182, 2014. http:// dx.doi.org/10. 1080/13562517.2013.836088

KLEIN, U. PETRA Projekt - Und Transferorientierte Ausbildug Grudlagen, Beispiele, Planungs - Und Arbeitsunterlagen. Munique: Siemens AG, 1990.

LAVILLE, C.; DIONE, J. A Construção do Saber: manual de metodologia da pesquisa em Ciências Humanas. Belo Horizonte: Editora UFMG, 1999.

LEMOS, D. C. et al. Uma Reflexão acerca do Ensino das Disciplina s de Recursos Humanos / Gestão de Pessoas nos Cursos de Graduação em Administração do Estado de Santa Catarina. SEMINÁRIOS EM ADMINISTRAÇÃO a(14), 2011, São Paulo, Anais... São Paulo: SEMEAD, 2011. 
LIBÂNEO, J. C. Os Objetivos e Conteúdos de Ensino. In: LIBÂNEO, J. C. Didática. 2. ed. São Paulo: Cortez, 2013.

LIMA, M. C. O Sentido da Educação no Contexto da Sociedade Pós-Moderna. Administração: Ensino e Pesquisa, v. 8, n. 1, p. 109-128, 2007.

MACHADO, N. J. Imagens do Conhecimento e Ação Docente no Ensino Superior. In: Cadernos de Pedagogia Universitária. São Paulo: USP, 2008.

MALHOTRA, N. K. Pesquisa de Marketing: foco na decisão. 3. ed. São Paulo: Pearson Prentice Hall, 2011.

MARCONI, M. A.; LAKATOS, E. M. Fundamentos de Metodologia Científica. 6. ed. São Paulo: Atlas, 2005.

MAROCO, J. Análise Estatística com Utilização do SPSS. Lisboa: Edições Silabo, 2010.

MATTAR, F. N. Pesquisa de Marketing: edição compactada. 4. ed. São Paulo: Atlas, 2008.

MCCLELLAND, D. C. The Achieving Society. New York: D. Van Nostrand, 1961.

McMANUS, T. E. Dreams, Visions and Values in Fundamental Business Education. Journal of Management Development, v.33, n. 1, p. 32-47, 2014. DOI https:// doi.org/10.1108/ JMD-11-2013-0134.

MITRE, S. M. et al. Metodologias Ativas de Ensino Aprendizagem na Formação Profissional em Saúde: Debates Atuais. Ciência \& Saúde Coletiva, v. 13, 2008. DOI http://dx.doi. org/10.1590/S1413-81232008000900018

MOREIRA, M. A. ã Behaviorismo, Humanismo e Cognitivismo (Um pseudo-organizador prévio). In: MOREIRA, M. A. Teorias de Aprendizagem. 2. ed. ampliada. São Paulo: Editora Pedagógica e Universitária, 2015.

MOREIRA, M. A. Al Final qué es Aprendizaje Significativo? Revista Qurriculum, La Laguna, n. 25, p. 29-56, 2012.

MOREIRA, M. A. Aprendizaje Significativo: teoria y práctica. Madrid: Visor, 2000.

PRADO, C.; VAZ, D. R.; ALMEIDA, D. M. Teoria da Aprendizagem Significativa: Elaboração e Avaliação de Aula Virtual na Plataforma Moodle. Revista Brasileira de Enfermagem, v. 64, n. 6, 2012. DOI http:// dx.doi.org/10.1590/S0034-71672011000600019

RANGEL, M. Fundamentos Pedagógicos: Referências Significativas Comuns ao Ensino nas Áreas de Estudo Gerais e Profissionalizantes. Boletim Técnico do Senac: A Revista da Educação Profissional, v. 36, n. 3, p.15-23,z 2010.

SALM, J.; LEAL, J. S. A Justiça Restaurativa: Multidimensionalidade Humana e seu Convidado de Honra. Sequência, n. 64, p. 195-226, 2012.

SANTOS, F. M. T. As Emoções nas Interações e a Aprendizagem Significativa. Ensaio pesquisa em Educação em Ciências, v. 9, n. 2, 2007. DOI http:/ / dx.doi.org/10.1590/198321172007090202 


\section{RODRIGUES ANTUNES, DANIELA MEIRELLES ANDRADE \& JADE VIEIRA}

SELLTIZ, C. Métodos de Pesquisa das Relações Sociais. São Paulo: Herder, 1965.

SERVIÇO BRASILEIRO DE APOIO ÀS MICRO E PEQUENAS EMPRESAS, Comportamento Empreendedor. Sebrae Nacional, 2017. Disponível em <http:/ / www.sebrae.com. $\mathrm{br} /$ sites/PortalSebrae/Programas / conheca-as-caracteristicas-empreendedoras-desenvolvidas-no-empretec,d071a5d3902e2410VgnVCM100000b272010aRCRD > 5.Acessado em 17 de julho de 2017.

SILVA, A. B.; REBELO, L. M. B. A Emergência do Pensamento Complexo nas Organizações. Revista de Administração Pública, v. 37, n. 4, p. 777-96, 2003.

SOUZA, C. S.; IGLESIAS, A. G.; PAZIN FILHO, A. Estratégias Inovadoras para Métodos de Ensino Tradicionais - Aspectos Adicionais - Aspectos Gerais, Medicina - Ribeirão Preto. v. 47, n. 3, p. 284-292, 2014.

SOUZA, C. V.; SHIGUTI, W. A.; RISSOLI, V. R. V. Metodologia Ativa para Aprendizagem Significativa com Apoio de Tecnologias Inteligentes. CONGRESSO INTERNACIONAL DE INFORMÁTICA EDUCATIVA (18), 2013, Porto Alegre, Anais... Porto Alegre: TISE, 2013. Disponível em: < http:/ / www.tise.cl/volumen9/TISE2013/653-656.pdf>. Acessado em 17 de julho de 2017.

TEKARSLAN, E.; ERDEN, N. S. A Review of Business Education around the Globe: Future Transitions. Journal of Multidisciplary Research. v.6, n. 2, p. 49-64, 2014.

URIAS, G. M. P. C. U.; AZEREDO, L. A. S. Metodologias Ativas nas Aulas de Administração Financeira: Alternativa ao Método Tradicional de Ensino para o Despertar da Motivação Intrínseca e o Desenvolvimento da Autonomia. Administração: Ensino e Pesquisa, v. 18, n. 1, p. 39-67, 2017.

YIN, R. K. Estudo de Caso: planejamento e métodos. 3. ed. Porto alegre: Bookman. 2005. 


\section{ANEXO I}

Questionário - Percepção dos alunos de Administração da Técnica de Ensino Multidimensional

Objetivo: Esse formulário destina-se aos alunos que cursaram a disciplina de Empreendedorismo Tecnológico do curso de Administração de Empresas da UNIFEI nos últimos cinco anos e tem como objetivo coletar informações para validar a efetividade da Técnica Multidimensional de Ensino como parte do aprendizado na disciplina. A técnica Multidimensional de Ensino é composta por três vertentes: (1) Indivíduo, (2) Teoria e (3) Sociedade. Considerando estes aspectos, bem como a sua vivência enquanto aluno ou ex-aluno desta disciplina, pedimos que nos auxilie com sua opinião, respondendo esse questionário.

Desde já agradecemos.

\section{Parte I - Informações Gerais}

1. Sexo: ( ) Feminino ( ) Masculino

2. Ano que cursou a disciplina: （）2012（）2013（）2014 ( ) 2015 ( ) 2016

3. Qual a sua idade: ( ) 17 ou menos ( ) 18 a 20 ( ) 21 a 23 ( ) 24 a $26($ ) 27 a $30($ ) Acima de 30

4. Já é formado? ( ) Sim ( ) Não

5. Fez a disciplina mais de uma vez? ( ) Sim ( ) Não

6. Caso a resposta anterior seja positiva, quantas vezes? ( ) 2() 3() 4 
7. Qual o nome da empresa que atuou no Projeto Caçadores de Anjos?

\begin{tabular}{|c|c|c|}
\hline ) Safe Trace & ( ) Web nas Nuvens & ) Trade-1 \\
\hline ) Dinheirama Online & ) CVS Sistemas & ) DreaMoney \\
\hline ) FEMTO Ciências & ) TR Soluções & ) O "X" da Questão \\
\hline ) Nexus & ) Nebovile & ) Inova GS \\
\hline ) Dares & ) Pando Aps & ) Smart M \\
\hline ) Keeplay & ) Metativa & ) Caderno Vivo \\
\hline ) Box Cards & ) Camaleon & ) $R Z X$ \\
\hline ) Ypoos & ( ) Dojo & \\
\hline
\end{tabular}

8. Qual a cidade da empresa do Projeto Caçadores de Anjos?

( ) Itajubá

( ) Santa Rita do Sapucaí

( ) São José dos Campos

( ) Franca

9. Qual foi sua dedicação Quinzenal ao Projeto Caçadores de Anjos?

( ) Até uma hora

( ) Acima de uma hora e até duas horas

( ) Acima de duas horas até três horas

( ) Acima de três horas até quatro horas

( ) Acima de quatro horas. 


\section{Parte II - Teoria}

10. Avalie o seu desenvolvimento teórico durante a disciplina, considerando o aprendizado a partir dos tópicos elencados abaixo. O valor 1 indica que o aprendizado não foi adquirido e 5 o que foi muito adquirido.

\section{Teorias Relacionadas}

Utilização e Elaboração do Canvas

Elaboração de Pitches

Ambientes de Inovação: Incubadoras, Parques

Tecnológicos e Aceleradoras

Ecossistemas Empreendedores

Investidores Anjos, Venture Capital e Private Equity

Informações necessárias para o Investidor-

Anjo: mercadoalvo, potencial do negócio,

concorrência, escalabilidade e time. 
11. Com relação a metodologia utilizada pelo professor em sala de aula, bem como exposição dos conteúdos, avalie as afirmações abaixo. Considere 1 para afirmações que você discorda totalmente e 5 para as que você concorda totalmente.

\section{Metodologia}

$\begin{array}{lllll}1 & 2 & 3 & 4 & 5\end{array}$

A explicação da proposta e conteúdo da disciplina explanadas no início do semestre foi cumprida como acordado.

A explicação das etapas do projeto "Caçadores de Anjos" foi suficiente para o desenvolvimento do projeto.

As aulas expositivas tiveram aplicação prática para o desenvolvimento do projeto "Caçadores de Anjos".

Houve disponibilidade do professor para solucionar as dúvidas que surgiram durante o semestre, a partir das atividades que foram propostas para a realização da disciplina.

12. Com relação ao sistema de avaliação da disciplina, avalie as afirmações abaixo considerando 1 para afirmações que você discorda totalmente e 5 para as que você concorda totalmente.

\section{Sistema de Avaliação}

$\begin{array}{lllll}1 & 2 & 3 & 4 & 5\end{array}$

As avaliações do semestre foram apresentadas no início do semestre.

Todas as avaliações foram cumpridas ao final do semestre.

As atividades avaliativas e seus pesos foram coerentes ao conteúdo da disciplina.

O resultado das avaliações foi disponibilizado dentro do prazo determinado. 


\section{Parte III - Indivíduo}

Considerando o seu desenvolvimento pessoal, bem como algumas das habilidades-chave pertencentes ao modelo PETRA, avalie o seu desenvolvimento pessoal, após a participação no Projeto "Caçadores de Anjos". Você deve considerar 1 para habilidades que não foram desenvolvidas e 5 para habilidades que foram bem desenvolvidas. Utilize essa escala para o bloco de questões da letra A e B.

\section{Bloco A}

\section{Habilidades Pessoais}

$\begin{array}{lllll}1 & 2 & 3 & 4 & 5\end{array}$

Autossuficiência: Execução e avaliação de um trabalho pelo próprio aluno a partir de critérios e procedimentos por ele próprio estabelecidos.

Capacidade de planejamento: Tomada de decisões sobre a realização de trabalho pelo próprio aluno; execução e avaliação de acordo com os procedimentos planejados.

Coordenação: Organização metódica das atividades planejadas, dentro do tempo previsto, para conseguir desenvolver o trabalho sem dificuldades.

Determinação: Desenvolvimento, com firmeza e sem vacilação, de ações planejadas que levam ao alcance dos objetivos pretendidos.

Precisão: Execução de um trabalho de acordo com as especificações técnicas definidas no projeto.

Zelo: Execução cuidadosa de um trabalho, com dedicação e responsabilidade.

Cooperação: Disposição de trabalhar eficazmente com outras pessoas em grupo; prontidão de oferecer espontaneamente ajuda aos outros, sem tirar proveito da situação.

Empatia: Tendência de "colocar-se no lugar dos outros", ou seja, saber lidar compreensivamente com opiniões e posições alheias. Integração: Adaptação de uma pessoa a um grupo e vice-versa.

Persuasão e Rede de Contatos: Utiliza estratégias que influenciar ou persuadir os outros; Utiliza pessoas-chave como agentes para atingir seus próprios objetivos; Age para desenvolver e manter relações comerciais. 
Liderança Emergencial: Tendência a "tomar as rédeas" do trabalho em grupo quando o assunto tratado pertencer à sua área de competência.

Participação/Trabalho em Equipe: Disposição de oferecer contribuições ao grupo; prontidão para ouvir opiniões alheias.

Expressão Oral e Escrita: Descrição oral ou escrita de fatos e pensamentos de forma clara, compreensível e adequada.

Disciplina: Disposição para cumprir obrigações, regras e papéisestabelecidas tanto pela própria pessoa, quanto pelo grupo, empresa ou sociedade. Envolvimento: Disposição para "vestir a camisa"; prontidão de responsabilizar-se, individualmente ou em grupo, pelos resultados obtidos no trabalho. Iniciativa: Disposição para assumir e desenvolver um trabalho de forma espontânea e rápida.

Flexibilidade: Adaptação, consciente e rápida, de ações e atitudes planejadas diante de situações que se modificam.

Perseverança: Manutenção, num mesmo nível, da capacidade de trabalho durante um longo período, mesmo diante de situações monótonas e repetitivas.

Correr Riscos calculados: age para reduzir os riscos ou controlar os resultados; Coloca-se em situações que implicam desafios ou riscos moderados. 
15. Avalie os benefícios gerados para você, por ter participado do Projeto "Caçadores de Anjos", considere 1 para afirmações que você discorda totalmente e 5 para as que você concorda totalmente.

\section{Benefícios da Participação no Projeto}

$\begin{array}{lllll}1 & 2 & 3 & 4 & 5\end{array}$

O projeto proporcionou oportunidade de aumento do seu networking.

Houve o aprendizado do negócio, um novo ramo de atuação ou o contexto que a empresa escolhida estava inserida.

O projeto gerou oportunidades futuras como estágio, consultoria ou sociedade nas empresas.

O contato com os investidores anjos ajudou em uma visão prática das negociações que acontecem entre as empresas.

A participação no projeto te inseriu em ambientes tecnológicos.

A participação no projeto lhe proporcionou a oportunidade de conhecer mais sobre Empresas de Base Tecnológica ou Startups. 


\section{Parte IV - Sociedade}

16. Avalie os contatos e as atividades realizadas com a empresa durante a execução do Projeto "Caçadores de Anjos", considere 1 para afirmações que você discorda totalmente e 5 para as que você concorda totalmente.

\section{Relacionamento com Empresas}

$\begin{array}{lllll}1 & 2 & 3 & 4 & 5\end{array}$

A atividades da empresa e sua atuação no mercado ficaram claras para o grupo.

Os dados sobre a empresa foram facilmente acessados.

O retorno das solicitações de informações feitas à empresa ocorria em tempo suficiente para a execução do trabalho.

Houve sigilo, por parte dos alunos, em relação as informações confidenciais obtidas das empresas. As agendas entre os empresários e investidores anjo foram conciliáveis para as entrevistas marcadas pelos alunos. 
17. Avalie os resultados oferecidos às empresas pelos alunos, considere 1 para afirmações que você discorda totalmente e 5 para as que você concorda totalmente.

\section{Resultados para as Empresas}

$\begin{array}{lllll}1 & 2 & 3 & 4 & 5\end{array}$

O Canvas elaborado pelo grupo foi utilizado pela empresa.

O pitch elaborado foi utilizado pela empresa.

Os alunos proporcionaram outras entregas para a empresa (como: folders, revisão do sumário executivo) que ajudaram na promoção do negócio.

A empresa melhorou seu modelo ou plano de negócios a partir dos contatos proporcionados pelos alunos.

O grupo buscou contatos além dos investidores anjos para auxiliar nos negócios da empresa.

O grupo aumentou a divulgação da empresa com os contatos proporcionados. 
18. Avalie os resultados oferecidos às empresas por meio dos investidores, considere 1 para afirmações que você discorda totalmente e 5 para as que você concorda totalmente.

\section{Investidores Anjos}

$\begin{array}{lllll}1 & 2 & 3 & 4 & 5\end{array}$

O grupo proporcionou contatos com investidores anjos ou grupos de investidores anjo.

As conversas entre empresários e investidores ajudaram a empresa a ter novas percepções do seu negócio.

Os contatos com os investidores anjos proporcionados pelo grupo ajudaram no networking da empresa.

Os investidores anjos intermediados pelo grupo ajudaram a empresa com mentorias sobre o foco do negócio.

Nas conversas entre investidores e empresários foram identificadas as possibilidades de projetos conjuntos entre eles.

O grupo cadastrou a empresa em bases de investimento anjo 


\section{Parte V - Avaliação da Técnica}

19. Avalie o uso da Técnica Multidimensional de Ensino para Administração, considere 1 para afirmações que você discorda totalmente e 5 para as que você concorda totalmente.

\section{$\begin{array}{lllllll}\text { Técnica Multidimensional de Ensino } & & 1 & 2 & 3 & 4 & 5\end{array}$}

Identifica-se uma relação teórica entre o conteúdo e as atividades desenvolvidas no Projeto "Caçadores de Anjos".

São criadas situações de aprendizado fora do contexto de sala de aula, onde o aluno pode desenvolver habilidades pessoais.

A troca de experiência entre alunos, empresários

e investidores "anjos" proporciona benefícios para as partes envolvidas.

O contato com empresários e investidores auxilia no processo de aprendizado.

A Técnica Multidimensional de Ensino pode ser uma alternativa ativa para o aprendizado dos alunos em Administração. 


\section{DADOS DOS AUTORES}

\section{ANDRÉA APARECIDA DA COSTA MINEIRO^andreamineiro@unifei.edu.br} Doutoranda em Empreendedorismo e Inovação pela UFLA

Instituição de vinculação: Universidade Federal de Itajubá Itajubá/MG - Brasil Áreas de interesse em pesquisa: Ensino em Administração (Ação Docente e Ambiente de Aprendizagem), Empreendedorismo e Inovação, Relação Universidade-Empresa.

${ }^{\star}$ Av. BPS, 1301 Pinheirinho Itajubá/MG

LUIZ GUILHERME RODRIGUES ANTUNES luguiantunes@yahoo.com.br Mestre em Administração pela UFLA

Instituição de vinculação: Universidade Federal de Lavras

Lavras/MG - Brasil

Áreas de interesse em pesquisa: Redes Interorganizacionais e Formação Docente.

DANIELA MEIRELLES ANDRADE daniela.andrade@dae.ufla.br

Doutora em Administração pela UFLA

Instituição de vinculação: Universidade Federal de Lavras

Lavras/MG - Brasil

Áreas de interesse em pesquisa: empreendedorismo, metodologia ativa, setor público.

JADE VIEIRA jade.vieira2697@gmail.com

Bacharel em Administração pela UNIFEI

Instituição de vinculação: Universidade Federal de Itajubá

Itajubá/MG - Brasil

Áreas de interesse em pesquisa: Educação empreendedora e metodologias ativas de ensino. 